\title{
Inhaled prostacyclin reduces cardiopulmonary bypass- induced pulmonary endothelial dysfunction via increased cyclic adenosine monophosphate levels
}

\author{
S. Fortier, $M D^{\mathrm{a}}$ \\ R. G. DeMaria, MD, PhD ${ }^{\mathrm{a}, \mathrm{c}}$ \\ Y. Lamarche, $M D^{\mathrm{a}}$ \\ 0. Malo, $\mathrm{MSc}^{\mathrm{a}}$ \\ A. Denault, MD ${ }^{\mathrm{b}}$ \\ F. Desjardins, $\mathrm{BSc}^{\mathrm{a}}$ \\ M. Carrier, MD \\ L. P. Perrault, MD, PhD
}

\footnotetext{
From Research Center and Department of Surgery a and Department of Anesthesiology, ${ }^{\mathrm{b}}$ Montreal Heart Institute, Montreal, Quebec, Canada; and Cardiovascular Surgery Unit, ${ }^{\mathrm{c}}$ Arnaud de Villeneuve Teaching Hospital, Montpellier, France.

Received for publication April 1, 2003; revisions requested Sept 25, 2003; accepted for publication Sept 29, 2003

Address for reprints: Louis P. Perrault, MD, $\mathrm{PhD}$, Research Center, Montreal Heart Institute, 5000 Belanger Street East, Montreal, Quebec H1T 1C8, Canada (E-mail: lpperrau@icm.umontreal.ca).

J Thorac Cardiovasc Surg 2004;128:109-16 $0022-5223 / \$ 30.00$

Copyright (C) 2004 by The American Association for Thoracic Surgery

doi:10.1016/j.jtcvs.2003.09.056
}

Objective: Cardiopulmonary bypass triggers a systemic inflammatory response that alters pulmonary endothelial function, which can contribute to pulmonary hypertension. This study was designed to demonstrate that inhaled prostacyclin, a selective pulmonary vasodilator prostaglandin, prevents pulmonary arterial endothelial dysfunction induced by cardiopulmonary bypass.

Methods: Three groups of Landrace swine were compared: control without cardiopulmonary bypass (control group); 90 minutes of normothermic cardiopulmonary bypass (bypass group); 90 minutes of cardiopulmonary bypass and treated with prostacyclin during cardiopulmonary bypass (continuous nebulization with continuous positive airway pressure until the end of the cardiopulmonary bypass; prostacyclin group). After 60 minutes of reperfusion, swine were put to death and pulmonary arteries harvested. After contraction to phenylephrine, endotheliumdependent relaxation to bradykinin and acetylcholine was studied in standard organ chamber experiments. The pulmonary artery intravascular cyclic adenosine monophosphate content was compared between the 3 groups (post-cardiopulmonary bypass).

Results: There was a statistically significant improvement of the endotheliumdependent relaxation to bradykinin in the prostacyclin group when compared with the bypass group $(P<.05)$. There was no statistically significant difference for endothelium-dependent relaxation to acetylcholine $(P>.05)$ between the prostacyclin and the bypass groups. There was a statistically significant decrease in the cyclic adenosine monophosphate content and a statistically significant increase of the mean pulmonary artery pressure in the bypass group only $(P<.05)$.

Conclusion: Prophylactic use of inhaled prostacyclin has a favorable impact on the pulmonary endothelial dysfunction induced by cardiopulmonary bypass associated with preservation of pulmonary intravascular cyclic adenosine monophosphate content and the pulmonary vascular tone.

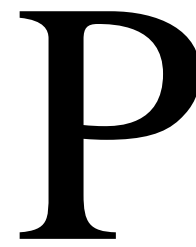

ostpump syndrome was identified early following the development of cardiopulmonary bypass (CPB) in the 1950s and is characterized by increased alveolo-arterial gradient $\left(\mathrm{A}-\mathrm{aDO}_{2}\right)$ and intrapulmonary shunt, decreased pulmonary compliance, and increased pulmonary vascular resistance and permeability ${ }^{1,2}$ and is related to the systemic inflammatory response associated with $\mathrm{CPB} .{ }^{3}$ Ischemia-reperfusion injury is the major cause of this syndrome but contact of blood with the nonphysi- 


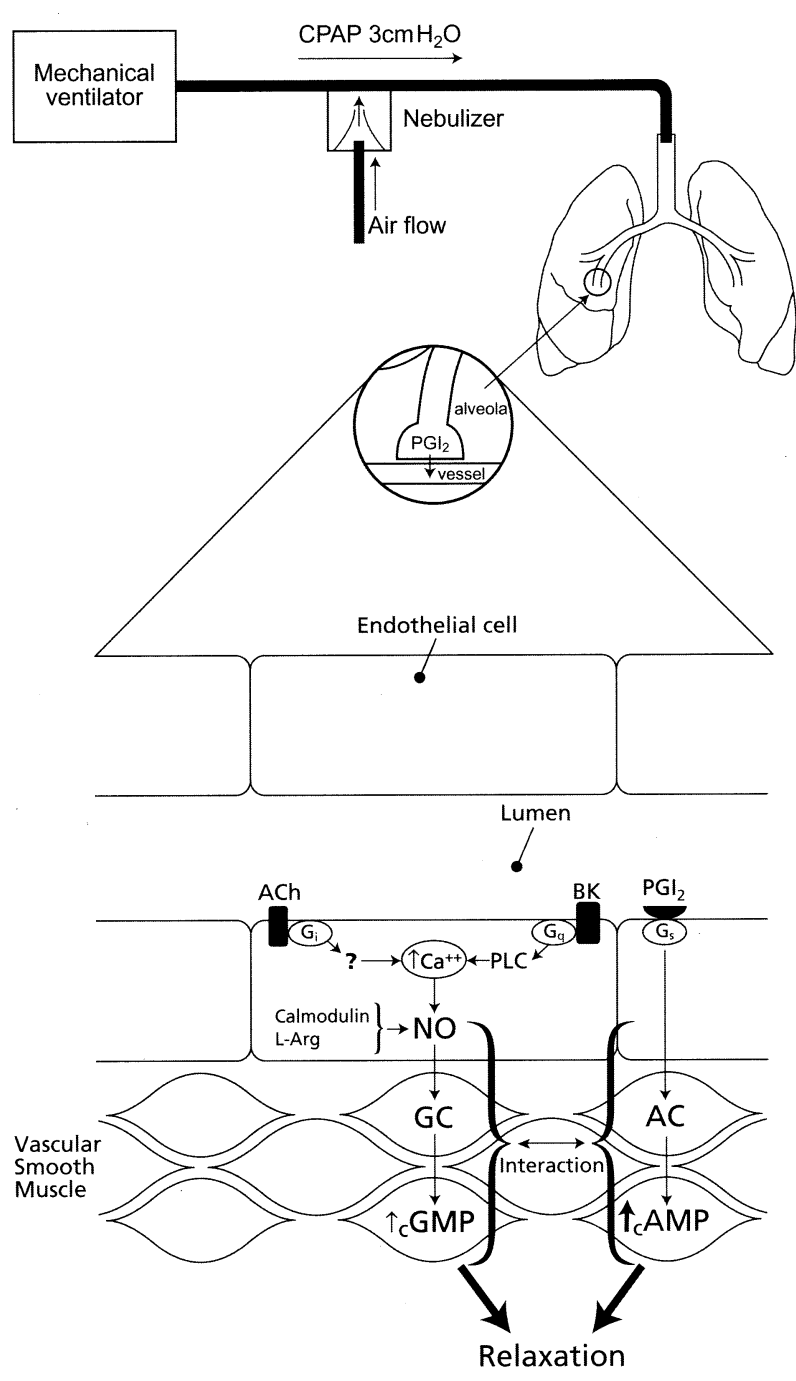

Figure 1. $\mathrm{PGI}_{2}$ was administered through an in-line nebulizer connected to the inspiratory limb of the ventilator. A CPAP was used during CPB to distribute the drug to the lungs. A summary of the endothelial transduction signal pathways for NO (through ACh and $\mathrm{BK}$ ) and for $\mathrm{PGI}_{2}$ is shown. See text for more details.

ological surface of the circuit and endotoxemia are also implicated in a cascade of events including activation of the complement system, induction of adhesion molecules, cytokine release, and neutrophil activation. The final pathway of this inflammatory process leads to activation and dysfunction of the endothelium. ${ }^{3,4}$

Pulmonary endothelium, presenting a total surface area of $200 \mathrm{~m}^{2}$ in adults, is in constant interaction with the blood elements. ${ }^{5}$ Beyond its roles as selective barrier, the endothelium allows inhibition of platelet aggregation and neutrophil adhesion and elaborates powerful vasoactive substances that control blood flow and vascular remodeling. Appropriate endothelial function results from the equilib- rium between endothelium-dependent relaxing factors (EDRF), such as nitric oxide (NO) and prostacyclin, and endothelium-dependent contracting factors (EDCF), such as endothelin. Endothelial dysfunction can be defined as an imbalance between relaxing factors and contracting factors and results in the loss of the normal protective role of the endothelium in the homeostasis of the vascular wall. ${ }^{6}$ In vascular reactivity studies, only the vasomotor control function of the endothelium is studied.

Prostacyclin $\left(\mathrm{PGI}_{2}\right)$ is an endogenous prostaglandin derived from arachidonic acid metabolism through the cyclooxygenase pathway in the vascular endothelium. $\mathrm{PGI}_{2}$ binds to a Gs-protein-related receptor, which when activated increases cyclic adenosine monophosphate (cAMP) concentration, activating a protein kinase $\mathrm{A}$ to decrease free intracellular calcium concentration (Figure 1). The physiological effects are vascular dilatation (predominantly in resistance vessels), inhibition of endothelin secretion, inhibition of platelet aggregation, and inhibition of leukocyte adhesion to the endothelium. ${ }^{7}$

In the cardiac surgery setting, $\mathrm{PGI}_{2}$ has been used in clinical situations such as pulmonary hypertension and the adult respiratory distress syndrome following $\mathrm{CPB} .{ }^{7,8}$ Intravenous infusion of $\mathrm{PGI}_{2}$ may increase intrapulmonary shunt and cause systemic vasodilatation that can be deleterious in hemodynamically unstable patients. ${ }^{7}$ Due to these systemic side effects, researchers have favored the bronchial tree as a route of administration ${ }^{9}$ because the aerosolized form of $\mathrm{PGI}_{2}$ causes a selective dilatation of the pulmonary vessels and improves right ventricular (RV) function and the cardiac output without systemic hypotension encountered with the intravenous administration.

A selective endothelial dysfunction of the pulmonary arterial tree involving relaxation mediated by muscarinic receptors to acetylcholine (Gi-coupled) following CPB in a porcine model was demonstrated in our laboratory. ${ }^{10}$ The aim of this experimental study in a porcine model was first to determine the effect of prophylactic use of inhaled $\mathrm{PGI}_{2}$ before CPB on the pulmonary endothelial function and second to examine its effect on hemodynamic data, on the $\mathrm{A}-\mathrm{aDO}_{2}$, and on pulmonary artery pressures.

\section{Materials and Methods}

\section{Experimental Surgery/Anesthesia (General Preparation)}

All experiments were performed using white Landrace swine (McGill University, Montreal, Quebec, Canada) of either gender, aged $8 \pm 1$ weeks and weighing $29.8 \pm 2.2 \mathrm{~kg}$. Animals were maintained and tested in accordance with the recommendations of the Guidelines on the Care and Use of Laboratory Animals issued by the Canadian Council on Animals and approved by a local ethics committee. Induction was achieved using mask ventilation with 2\% isoflurane (Abbott Laboratories, Limited, St Laurent, Quebec, Canada). They were subsequently intubated and mechan- 
ically ventilated with a constant oxygen/air mixture $\left(3: 2, \mathrm{FIO}_{2}\right.$ $68 \%$ ) at 14 breaths $/ \mathrm{min}$ and tidal volume of 6 to $8 \mathrm{~mL} / \mathrm{kg}$. Anesthesia was maintained with $1 \%$ isoflurane inhalation. Following skin preparation and draping with sterile field, a Swan-Ganz catheter (Edwards Lifesciences, Irving, Calif) was inserted through the jugular vein to measure pulmonary artery pressure. Arterial and venous blood gases were measured at regular intervals during the experiment and maintained within physiological limits $(\mathrm{pH} 7.35-$ 7.45 and $\mathrm{PaCO}_{2} 35-45 \mathrm{~mm} \mathrm{Hg}$ ) by adjusting ventilation rate and tidal volume. The electrocardiogram was recorded from 3 subcutaneous limb electrodes.

\section{Experimental Groups}

Group 1: Control $(\boldsymbol{n}=\mathbf{6})$. The mediastinum was exposed via a median sternotomy. Heparin (300 UI/kg; Leo Pharma, Inc, Ajax, Ontario, Canada) was given intravenously. After 1 hour of general anesthesia with $1 \%$ isoflurane, the animal was exsanguinated and the heart and lung harvested.

To study the effect of these drugs on pulmonary vascular reactivity, a preliminary experiment was conducted. Four animals underwent median sternotomy. After 1 hour of general anesthesia with $1 \%$ isoflurane, anesthesia was changed to propofol for 1.5 hours $(0.1-0.2 \mathrm{mg} / \mathrm{kg} / \mathrm{min}$, same dosage as in the CPB groups), followed by 1 hour with $1 \%$ isoflurane to match the time and drugs used in the other groups. Arterial pressure was maintained with crystalloid (Ringer's lactate). The animal was then exsanguinated and the lungs harvested. Endothelium-dependent relaxation to bradykinin (BK) and acetylcholine ( $\mathrm{ACh}$ ) was comparable to the control group used in the study (data not shown). These organ chamber experiments confirmed that normal animals could be used as parallel control animals.

Group 2: Cardiopulmonary Bypass $(n=6)$. After sternotomy, the aorta and right atrium were cannulated following heparin administration (300 UI/kg), when activated coagulation time (ACT, assessed with Hemochron 801; Technidyne, Edison, NJ) was superior to 300 seconds. CPB was initiated when ACT was superior to 400 seconds. Ventilation and isoflurane were stopped but a continuous positive airway pressure (CPAP) of $3 \mathrm{~cm} \mathrm{H}_{2} \mathrm{O}$ was maintained throughout the $\mathrm{CPB}$ period. Anesthesia was maintained with a continuous infusion of propofol $(0.1-0.2 \mathrm{mg} / \mathrm{kg} / \mathrm{min})$. The pump flow was adjusted to obtain an index of $2.4 \mathrm{~L} / \mathrm{min} / \mathrm{m}^{2}$ and assessed by venous gases to maintain mixed venous saturation over $60 \%$. $\mathrm{FIO}_{2}$ was kept constant at a level of $68 \%$. Mean systemic arterial pressure was maintained between 50 and $70 \mathrm{~mm} \mathrm{Hg}$ with crystalloid (Ringer's lactate). The temperature was allowed to drift to $36^{\circ} \mathrm{C}$. The heart was left beating, empty. No aortic crossclamping or cardioplegic solution was used. Before $\mathrm{CPB}$ weaning, swine were rewarmed to $38^{\circ} \mathrm{C}$ (normal porcine temperature). After 90 minutes of $\mathrm{CPB}$, mechanical ventilation and isoflurane anesthesia were reinstituted and $\mathrm{CPB}$ was weaned. No protamine was given due to its potential cardiovascular effects such as complement activation and NO production. ${ }^{11}$ Normal circulation was restored for 60 minutes, at which time the animal was exsanguinated into the cardiotomy reservoir. The beating heart and the lungs were excised "en bloc" and immediately immersed in a cold modified Krebs-bicarbonate solution (composition in mmol/L: $\mathrm{NaCl} 118.3$, $\mathrm{KCl}$ 4.7, $\mathrm{MgSO}_{4}$ 1.2, $\mathrm{KH}_{2} \mathrm{PO}_{4}$ 1.2, glucose 11.1, $\mathrm{CaCl}_{2}$ 2.5, $\mathrm{NaHCO}_{3} 25$, and ethylenediaminotetraacetic acid 0.026).
Group 3: Cardiopulmonary Bypass and Inhaled Prostacyclin $(n=5)$. The same procedure was followed as in the CPB group (group 2). The only difference was that a bolus of 2 to $2.5 \mu \mathrm{g} / \mathrm{kg}$ of $\mathrm{PGI}_{2}$ was given via the endotracheal tube through a nebulizer during the 30 minutes preceding the initiation of CPB (Figure 1). Ventilation was then stopped but a continuous nebulization of $\mathrm{PGI}_{2}$ at a rate of $0.1 \mu \mathrm{g} / \mathrm{kg} / \mathrm{min}$ with CPAP of $3 \mathrm{~cm} \mathrm{H} \mathrm{H}_{2} \mathrm{O}$ was then instituted until the end of the CPB. Before weaning of $\mathrm{CPB}$, nebulization was stopped and ventilation reinstituted. The dosages were based on review of the literature ${ }^{7}$ and our experience with this medication. . $^{8}$

$\mathrm{PGI}_{2}$ (Flolan, Glaxo Wellcome, Mississauga, Ontario, Canada) was given as epoprostenol salt $1.5 \mathrm{mg}$ dissolved in $100 \mathrm{~mL}$ of sterile glycine buffer diluent for a concentration of $15 \mu \mathrm{g} / \mathrm{mL}$. The drug was administered through a conventional in-line nebulizer kit (Salter Labs, Arvin, Calif) connected to the inspiratory limb of the ventilator.

\section{Hemodynamic and Biochemical Data}

Arterial and venous blood gases were measured at regular intervals during the experiment (baseline, during $\mathrm{CPB}$, immediately after weaning from $\mathrm{CPB}$, and at death) Pulmonary artery pressures were measured with a Swan-Ganz catheter at different intervals during the procedure: after induction, before $\mathrm{CPB}$, and after weaning of CPB (0 minute, 10 minutes, 15 minutes, 45 minutes, and 60 minutes).

\section{Vascular Reactivity Studies}

Less than 10 minutes after en bloc excision, the heart was removed and the primary pulmonary artery was dissected. Branches of second-degree pulmonary arteries were isolated and dissected free of connective and adventitial tissue and divided into rings $(4 \mathrm{~mm}$ wide; 16 rings per animal). All rings were placed in organ chambers (Emka Technologies Inc, Paris, France) filled with $20 \mathrm{~mL}$ modified Krebs-bicarbonate solution continuously heated at $37^{\circ} \mathrm{C}$ and oxygenated with a carbogen mixture $\left(95 \% \mathrm{O}_{2}\right.$ and $\left.5 \% \mathrm{CO}_{2}\right)$. The rings were suspended between 2 metal stirrups with the upper 1 connected to an isometric force transducer connected to a signal amplifier and then allowed to stabilize for 30 minutes. Data were collected with a biological signal data acquisition software (IOX 1.203; Emka Technologies Inc). Each arterial ring was stretched to the optimal point of its active length-tension curve $(3.5 \mathrm{~g})$ as determined by measuring the contraction to potassium chloride (KCl) $60 \mathrm{mmol} / \mathrm{L}$ at different levels of stretch (data not shown). The maximal contraction of rings was then obtained with addition of potassium chloride $(\mathrm{KCl} 60 \mathrm{mmol} / \mathrm{L})$. After obtainment of a plateau, all baths were washed twice with modified Krebs-bicarbonate solution and indomethacin $\left(10^{-5} \mathrm{mmol} / \mathrm{L}\right.$; to exclude production of endogenous prostanoids) was added in each bath. After 60 minutes of stabilization, phenylephrine (PE; range $2 \times 10^{-7}$ $\mathrm{mol} / \mathrm{L}$ to $3 \times 10^{-6} \mathrm{~mol} / \mathrm{L}$ ) was added to obtain a contraction averaging $50 \%$ of the maximal contraction to $\mathrm{KCl}$.

Endothelium-Dependent Relaxation. The NO-mediated relaxation pathway was studied by constructing concentration-response curves to ACh $\left(10^{-10}\right.$ to $10^{-5} \mathrm{~mol} / \mathrm{L}$; an agonist of $\mathrm{M}_{2}$ receptors coupled to Gi-proteins) and to $\left(10^{-12}\right.$ to $10^{-6} \mathrm{~mol} / \mathrm{L}$; an agonist of $\mathrm{B}_{2}$ receptors coupled to Gq-proteins). 


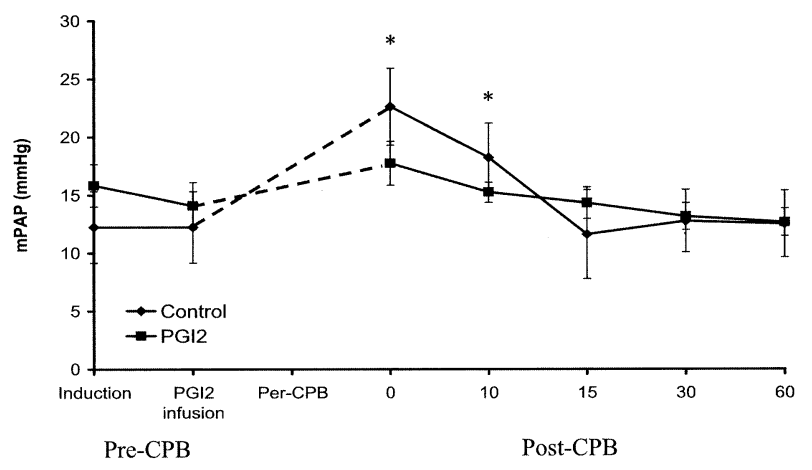

Figure 2. Mean pulmonary artery pressures (mPAP) with and without $\mathrm{PGI}_{2}$ before, during, and after $\mathrm{CPB} .{ }^{*} P<.05$ post-CPB versus pre-CPB (group without $\mathrm{PGI}_{2}$ only).

Endothelium-Independent Relaxation. At the end of the experiment, endothelium-independent relaxation was studied with the use of $10^{-5} \mathrm{~mol} / \mathrm{L}$ sodium nitroprusside (SNP), a nitric oxide donor.

\section{Drugs}

All drugs were prepared daily. ACh, BK, indomethacin, and sodium SNP were obtained from Sigma Chemical Co (Oakville, Ontario, Canada). Phenylephrine was obtained from Cayman Chemical Company (Ann Arbor, Mich).

\section{Determination of Pulmonary Artery Intravascular cAMP Content}

To determine the vascular content of porcine pulmonary arteries, rings from the 3 groups were collected after death, frozen in liquid nitrogen, and stored at $-70^{\circ} \mathrm{C}$. At the time of analysis, all segments were pulverized in a liquid nitrogen-cooled stainless steel mortar, and then transferred in trichloracetic acid solution $(6.25 \%$ $\mathrm{w} / \mathrm{v})$. The acid extracts were then centrifuged at $4^{\circ} \mathrm{C}$ for 15 minutes at $12,000 \mathrm{~g}$ (3000 revolutions per minute) to precipitate cell debris and proteins. The pellets were used for total protein determination using the Bradford microassay technique (Bio-Rad, Mississauga, Ontario, Canada). To remove trichloracetic acid, the supernatants were extracted 4 times with water-saturated diethyl ether. Any residual diethyl ether was removed by heating the samples to $90^{\circ} \mathrm{C}$ for 3 to 5 minutes. cAMP quantification was done using an enzyme immunoassay system with acetylation based on rabbit anti-cAMP antibody (Amersham Pharmacia Biotech, Baie d'Urfé, Quebec, Canada). The amount of cAMP in each blood vessel ring was standardized to $\mathrm{pmol} \mathrm{cAMP} \cdot \mathrm{mg}^{-1}$ protein.

\section{Total Antioxidant Plasma Status}

The assay antioxidant levels in plasma samples rely on the ability of antioxidants in the sample to inhibit the oxidation of ABTS (2,2'-Azino-di-[3-ethylbenzthiazoline sulphonate]) to $\mathrm{ABTS}^{+}$by metmyoglobin (a peroxidase). The amount of $\mathrm{ABTS}^{+}$produced can be monitored by reading the absorbance at $600 \mathrm{~nm}$. Under the reaction conditions used, the antioxidants in the sample cause suppression of the absorbance at $600 \mathrm{~nm}$ to a degree that is proportional to their concentration. Blood samples from groups were drawn from right atrium before and after CPB in ethylenediaminetetraacetic acid to prevent coagulation and subsequently were centrifuged. The isolated plasma was then frozen and kept at $-70^{\circ} \mathrm{C}$ until analysis. The plasma samples were analyzed with Total Antioxidant status activity Assay Kit (Calbiochem, San Diego, Calif). The concentration of $\mathrm{ABTS}^{+}$were measured with a spectrophotometer set at $600 \mathrm{~nm}$.

\section{Statistical Analysis}

All values are expressed as the mean \pm standard error of the mean (SEM). Contractions to $\mathrm{PE}$ are expressed as a percentage of the maximal contraction to $\mathrm{KCl}(60 \mathrm{mmol} / \mathrm{L})$. Relaxations are expressed as the percentage of the maximal contraction to PE for each ring. Two-way analyses of variance (ANOVA) were performed with 1 repeated measure (ACh and $\mathrm{BK}$ doses) to compare the concentration-response curves between the 3 groups, followed by pairwise comparisons when the global ANOVA was significant. One-way ANOVA was performed to compare groups for contractions and cAMP. Two-way ANOVA was performed with 1 repeated measure (time) to compare the hemodynamic data (mean arterial pressure [mAP], mean pulmonary artery pressure [mPAP], pulmonary vascular resistance index [PVRI], $\mathrm{SvO}_{2}, \mathrm{~A}-\mathrm{aDO}_{2}$, lactic acid levels), followed by pairwise comparisons when the global ANOVA was significant. Statistical analysis was performed with the computer software SAS (SAS Institute, Inc, Cary, NC).

\section{Results}

\section{Hemodynamic and Biochemical Data}

Following CPB, there was a statistically significant elevation of the mPAP at 0 and 10 minutes $(P<.05$; Figure 2$)$. In the group treated with $\mathrm{PGI}_{2}$, this elevation was not observed and the mPAP was more constant. There was a statistically significant increase of the $\mathrm{A}-\mathrm{aDO}_{2}$ after $\mathrm{CPB}$ in the group without $\mathrm{PGI}_{2}(P<.05)$, but not in the group with $\mathrm{PGI}_{2}$ (Table 1).

Lactic acid levels were elevated after CPB in both groups. The $\mathrm{SvO}_{2}$ level was decreased in both $\mathrm{CPB}$ groups after CPB. There was no statistically significant difference in lactic acid and $\mathrm{SvO}_{2}$ levels after $\mathrm{CPB}$ between the 2 groups. There was no statistically significant difference in the mAP, the $\mathrm{pH}$, and the PVRI $(P>.05$; Table 1$)$. There was no statistically significant difference in the mAP before and during $\mathrm{PGI}_{2}$ nebulization $(66 \pm 6$ vs $65 \pm 5 ; P>.05)$.

\section{Vascular Reactivity Study}

Contractions. The amplitude of the contraction to $\mathrm{KCl}$ (60 mmol/L) and to PE and the concentration of PE used were quantified for both groups in Table 2. The amplitude of contraction to $\mathrm{KCl}$ (endothelium-independent agent) was significantly lower in the control group and higher in the $\mathrm{CPB}$ group without $\mathrm{PGI}_{2}$. Conversely, there was no difference in contraction to $\mathrm{PE}$ (endothelium-dependent agent) between the $2 \mathrm{CPB}$ groups, but the $\mathrm{CPB}$ group without $\mathrm{PGI}_{2}$ required a significantly higher $\mathrm{PE}$ concentration to achieve the same level of contraction $(P<.05)$. 
TABLE 1. Hemodynamic and respiratory data of swine after CPB with or without $\mathbf{P G I}_{2}$

\begin{tabular}{|c|c|c|c|c|c|c|}
\hline & mAP & mPAP & PVRI & LA & $\mathrm{SvO}_{2}$ & $\mathrm{~A}-\mathrm{aDO}_{2}$ \\
\hline \multicolumn{7}{|l|}{ Baseline } \\
\hline CPB & $73 \pm 5$ & $12 \pm 3$ & $150 \pm 31$ & $2.6 \pm 0.2$ & $69 \pm 2$ & $188 \pm 23$ \\
\hline $\mathrm{PGI}_{2}$ & $66 \pm 6$ & $16 \pm 2$ & $151 \pm 22$ & $3.1 \pm 0.6$ & $77 \pm 2$ & $171 \pm 33$ \\
\hline \multicolumn{7}{|c|}{ Post-CPB } \\
\hline CPB & $73 \pm 5$ & $23 \pm 3^{*}$ & $179 \pm 31$ & $5.2 \pm 0.6^{*}$ & $53 \pm 2^{*}$ & $265 \pm 32^{*}$ \\
\hline $\mathrm{PGI}_{2}$ & $67 \pm 11$ & $118 \pm 2$ & $171 \pm 12$ & $6.4 \pm 1.8^{*}$ & $61 \pm 8^{*}$ & $210 \pm 16$ \\
\hline
\end{tabular}

$\overline{m A P}$, Mean arterial pressure $(\mathrm{mm} \mathrm{Hg}) ; m P A P$, mean pulmonary artery pressure $(\mathrm{mm} \mathrm{Hg})$; $P V R I$, pulmonary vascular resistance index (dynes sec $\left.\mathrm{m}^{2} / \mathrm{cm}^{5}\right)$; $L A$, lactic acid $(\mathrm{mmol} / \mathrm{L}) ; \mathrm{SvO}_{2}$, venous saturation in $\mathrm{O}_{2}(\%)$; $A-\mathrm{aDO}_{2}$, alveolo-arterial gradient $(\mathrm{mm} \mathrm{Hg}) ; C P B$, cardiopulmonary bypass; $P G I_{2}$, prostacyclin. Data are shown as means \pm SEM.

${ }^{*} P<.05$ pre- versus post-CPB.

Endothelium-Dependent Relaxation. There was a statistically significant decrease of endothelium-dependent relaxation to $\mathrm{ACh}$ in both $\mathrm{CPB}$ groups when compared with controls $(P<.05$; Figure 3,A). However, there was no statistically significant difference between the CPB group with $\mathrm{PGI}_{2}$ and the CPB group without $\mathrm{PGI}_{2}(P>.05)$.

There was a statistically significant decrease in endothelium-dependent relaxation to BK in the CPB group without $\mathrm{PGI}_{2}$ when compared with the control group $(P<.05)$ and a greater maximal relaxation to $\mathrm{BK}$ in the group with $\mathrm{PGI}_{2}$ when compared with the $\mathrm{CPB}$ group $(P<.05$; Figure $3, B)$. There was no statistically significant difference between the $\mathrm{PGI}_{2}$ and the control groups $(P>.05)$.

Endothelium-Independent Relaxation. No statistically significant difference in relaxation to the SNP was observed between groups, with all rings achieving 100\% relaxation (data not shown).

\section{Influence of Indomethacin}

In some baths, indomethacin was not added in order to eliminate its influence on $\mathrm{PGI}_{2}$. No statistically significant difference in contraction to $\mathrm{KCl}$ or $\mathrm{PE}$ or relaxation to $\mathrm{ACh}$ or BK was demonstrated in baths with and without indomethacin between the 3 groups (data not shown).

\section{Pulmonary Artery Intravascular cAMP Content}

There was a statistically significant lower cAMP content in the vascular rings of the CPB group without $\mathrm{PGI}_{2}$ when compared with the controls and with the $\mathrm{CPB}$ group with $\mathrm{PGI}_{2}(P<.05$; Figure 4$)$.

\section{Total Antioxidant Plasma Status}

There was no statistically significant difference in the total antioxidant plasma status between both CPB groups (CPB $0.55 \mathrm{mmol} / \mathrm{L} \pm 0.10 \mathrm{pre}-\mathrm{CPB}$ and $0.62 \mathrm{mmol} / \mathrm{L} \pm 0.08$ post-CPB; $\mathrm{PGI}_{2} 0.61 \mathrm{mmol} / \mathrm{L} \pm 0.05 \mathrm{pre}-\mathrm{CPB}$ and 0.56 $\mathrm{mmol} / \mathrm{L} \pm 0.03$ post-CPB; $P>.05$ ).
TABLE 2. Contraction to $\mathrm{KCl}(60 \mathrm{mmol} / \mathrm{L})$ and $\mathrm{PE}$ of porcine pulmonary arteries after CPB with or without $\mathrm{PGI}_{2}$

\begin{tabular}{lccc}
\hline & \multicolumn{3}{c}{ Group } \\
\cline { 2 - 4 } & $\begin{array}{c}\text { Control } \\
(\mathbf{n}=\mathbf{6})\end{array}$ & $\begin{array}{c}\mathbf{C P B} \\
(\mathbf{n}=\mathbf{6})\end{array}$ & $\begin{array}{c}\mathbf{P G I}_{\mathbf{2}} \\
(\mathbf{n}=\mathbf{5})\end{array}$ \\
\hline $\mathrm{KCl}(60 \mathrm{mmol} / \mathrm{L})(\mathrm{g})$ & $5.1 \pm 0.3 \dagger \ddagger$ & $7.5 \pm 0.4 \S$ & $6.1 \pm 0.3$ \\
$\mathrm{PE}(\mathrm{g})$ & $3.0 \pm 0.2 \dagger \ddagger$ & $4.1 \pm 0.3$ & $4.5 \pm 1.7$ \\
$\% \mathrm{PE} / \mathrm{KCl}$ & $61 \pm 1 \dagger \ddagger$ & $55 \pm 2 \S$ & $76 \pm 2$ \\
Dosage of $\mathrm{PE}\left(10^{-7} \mathrm{~mol} / \mathrm{L}\right)^{*}$ & $5.5 \pm 0.9 \dagger$ & $18.8 \pm 1.7 \S$ & $6.5 \pm 0.6$
\end{tabular}

$K C l$, potassium chloride; $P E$, phenylephrine; $C P B$, cardiopulmonary bypass; $P G I_{2}$, prostacyclin. Data are shown as mean \pm SEM.

*For achieving target level of contraction.

$\dagger P<.05$ control versus CPB.

$\ddagger P<.05$ control versus $\mathrm{PGI}_{2}$.

$\S P<.05$ CPB versus $P \mathrm{Pl}_{2}$.

\section{Discussion}

The aim of the present study was to document the effect of prophylactic use of inhaled $\mathrm{PGI}_{2}$ during $\mathrm{CPB}$. The major findings are the following: (1) inhaled $\mathrm{PGI}_{2}$ prevents the increase of the mPAP following CPB; (2) $\mathrm{PGI}_{2}$ is associated with a lower increase of the $\mathrm{A}-\mathrm{aDO}_{2}$; (3) animals receiving $\mathrm{PGI}_{2}$ had a maximal response of the pulmonary endothelium-dependent relaxation involving receptors coupled to Gq-proteins but no change in the pathway involving receptors coupled to Gi-proteins; and (4) the administration of $\mathrm{PGI}_{2}$ is associated with preservation of pulmonary arterial cAMP content after CPB.

Congenital and adult heart surgery such as mitral valve replacement are commonly followed by pulmonary hypertension in the postoperative period. ${ }^{13} \mathrm{CPB}$ can directly cause pulmonary vascular injury. Endothelial dysfunction may leave the pulmonary adrenergic system unopposed, with an increase in vascular tone, which can result in RV failure and low output syndrome. ${ }^{13}$ Morita and colleagues ${ }^{14}$ demonstrated in a porcine model that CPB causes a significant increase in pulmonary vascular resistance and depresses the RV function by more than $50 \%$. Several studies have demonstrated that RV dysfunction is a negative prognostic factor after cardiac surgery. Perioperative mortality ranges from $44 \%$ to $86 \%$ in patients with RV dysfunction. ${ }^{15}$ Furthermore, RV systolic dysfunction has been shown to be associated with poor outcome in patients undergoing myocardial revascularization with reduced left ventricular function. ${ }^{16}$ After CPB, pulmonary hypertension can be prevented by avoidance of hypoxia, hypercarbia, acidosis, and hypothermia as well as optimization of airway pressures and depth of anesthesia. ${ }^{13}$

Numerous experimental and human studies have demonstrated elevation of $\mathrm{PGI}_{2}$ levels during $\mathrm{CPB}$ with return to the baseline level immediately following $\mathrm{CPB} .{ }^{17}$ As the relative decrease of $\mathrm{PGI}_{2}$ following $\mathrm{CPB}$ may explain the rise in pulmonary artery pressure, our main hypothesis was 
Inhaled Prostacyclin and Endothelial Function

of Porcine Pulmonary Arteries

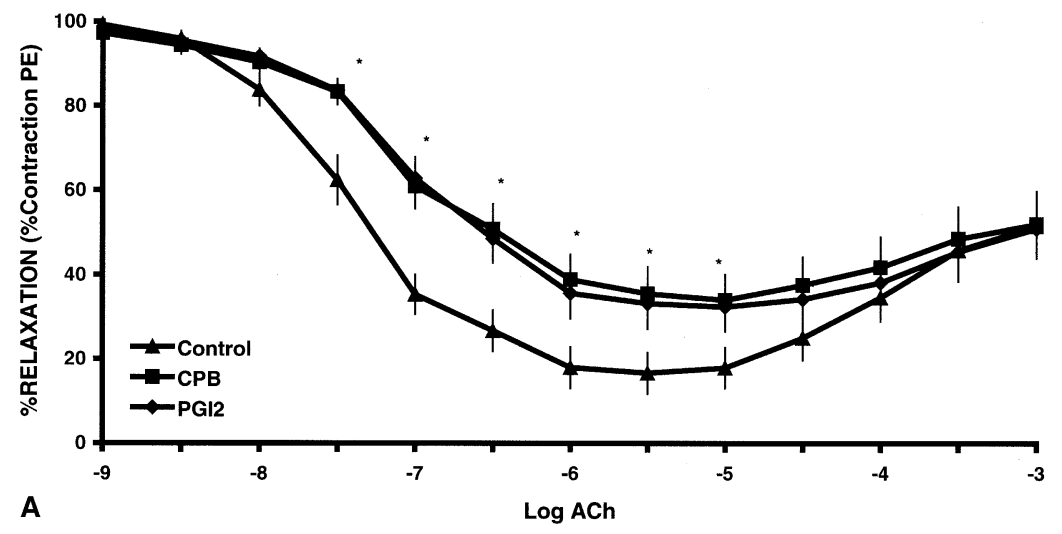

Inhaled Prostacyclin and Endothelial Function of Porcine Pulmonary Arteries

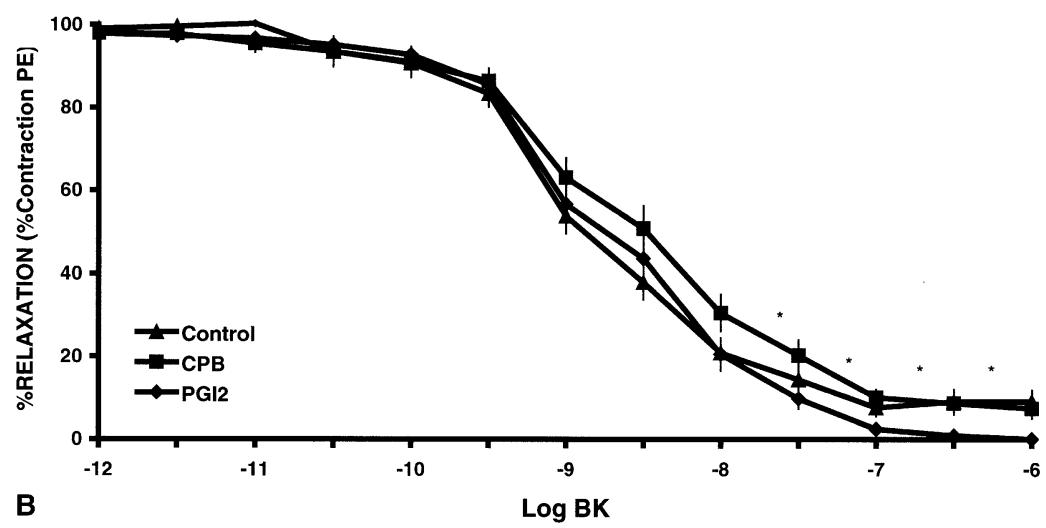

Figure 3. Cumulative concentration-response curves to (A) acetylcholine (ACh) and to $(B)$ bradykinin (BK) in rings of porcine pulmonary arteries with endothelium. Results are presented as the means \pm SEM. The asterisks indicate statistically significant difference between both CPB groups and control $(*)$, between control and CPB groups (**), and between CPB and $\mathrm{PGI}_{2}$ groups $\left(^{* * *}\right)(P<.05)$.

that $\mathrm{PGI}_{2}$ loading before $\mathrm{CPB}$ could prevent the pulmonary artery pressure elevation and secondary RV dysfunction.

In humans, pulmonary hypertension is defined as an mPAP of more than $25 \mathrm{~mm} \mathrm{Hg}$ but no such definition exists in swine. The results of the present study demonstrate that administration of inhaled $\mathrm{PGI}_{2}$ before CPB effectively attenuates pulmonary artery pressure elevation secondary to $\mathrm{CPB}$. Also, the adverse systemic effects of inhaled $\mathrm{PGI}_{2}$ on oxygen exchange are minimal due to its pulmonary selectivity, ${ }^{8}$ as shown by the absence of hypotension and preservation of the $\mathrm{A}-\mathrm{aDO}_{2}$ in the $\mathrm{PGI}_{2}$ group compared with the CPB only group. The inhaled route of delivery is most likely responsible for the improvement in A-a gradient in this model.

Contraction to $\mathrm{KCl}$ is a receptor-independent response of vascular smooth cells. Contractions with $\mathrm{KCl}$ were greater in the $\mathrm{CPB}$ group without $\mathrm{PGI}_{2}$. However, a higher concen- tration of PE was necessary to achieve the same level of contraction in the aforementioned group than in the CPB group with $\mathrm{PGI}_{2}$, which can be explained by a decreased number of pulmonary $\alpha$-receptors or reduced sensitivity of these receptors. In humans, CPB is associated with an impairment of $\alpha$-adrenergic responsiveness, apparently due to desensitization of $\alpha$-receptors. ${ }^{18}$ This may be due to the influence of hemodilution, hypothermia, alteration of drug pharmacokinetics, or increased level of plasmatic catecholamines. ${ }^{18}$ One explanation for the better $\alpha$-adrenergic responsiveness in the $\mathrm{PGI}_{2}$ group comes from the findings from Wachtogel and colleagues. ${ }^{19}$ The loss of platelet $\alpha$-adrenergic receptors during extracorporeal circulation is prevented with prostaglandin $\mathrm{E}_{1}\left(\mathrm{PGE}_{1}\right),{ }^{19}$ a vasodilator prostaglandin similar in structure and effects to $\mathrm{PGI}_{2} \cdot{ }^{17}$

A decreased pulmonary production of $\mathrm{NO}$ after $\mathrm{CPB}$ has been demonstrated in numerous studies. ${ }^{14,20} \mathrm{ACh}$ induces a 


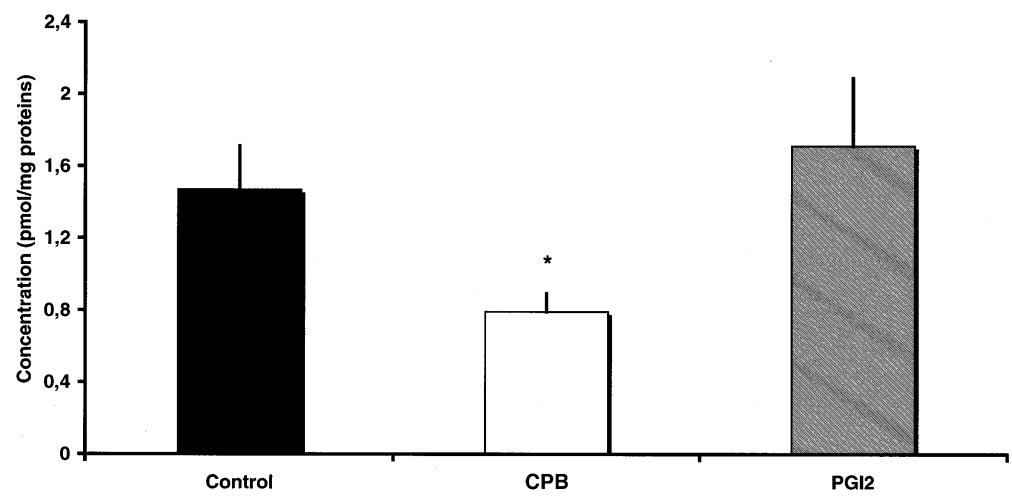

Figure 4. Pulmonary artery intravascular cAMP content in the control group and the CPB group following death. Results are presented as the mean \pm SEM. The asterisks (*) indicate statistically significant difference between the CPB group and the control and $\mathrm{PGI}_{2}$ groups $(P<.05)$.

dose-dependent vasomotor effect dependent on the preexisting vascular tone. Under resting conditions, ACh induces vasoconstriction and vasodilatation under conditions of elevated tone. ${ }^{21}$ ACh-related NO pathway appears to be preferentially damaged. ${ }^{10,22}$ Indeed, Gagnon and colleagues ${ }^{10}$ have shown in a porcine model that $\mathrm{CPB}$ with reperfusion of the pulmonary tree induces a decrease in endotheliumdependent relaxation mediated by muscarinic receptors, which was also demonstrated in a dog model by Zanaboni and colleagues. ${ }^{22}$ Although ACh induces endothelium-dependent relaxation through both the NO and cAMP pathways, ${ }^{23}$ more specific signal transduction pathways alterations may explain the lack of benefit of inhaled $\mathrm{PGI}_{2}$ in ACh-induced dysfunction in this study.

$\mathrm{BK}$ is an agonist that binds to $\mathrm{B}_{2}$ receptors coupled to Gq-proteins, which causes release of NO in pulmonary endothelium but also stimulates prostacyclin release, ${ }^{21}$ resulting in vasodilatation independently of the preexisting vascular tone. This study demonstrates complete relaxation of the pulmonary rings with $\mathrm{BK}$ after $\mathrm{PGI}_{2}$ administration, which can be attributed to this prostacyclin stimulation. This interaction between cAMP and NO has been recently studied in canine coronary arteries in which activation of the cAMP signal transduction increases endothelial NO production. ${ }^{24}$

$\mathrm{PGI}_{2}$ binds to Gs-protein receptors and induces an increase in cAMP concentration. In this study, CPB causes a significant decrease in cAMP content. However, administration of inhaled $\mathrm{PGI}_{2}$ before $\mathrm{CPB}$ increases these levels and prevents its subsequent decrease. These data indicate that cAMP signal transduction may be an important potential compensatory pathway to the dysfunctional NO pathway.

The CPB-induced systemic inflammatory response contributes to the release of reactive oxygen species (ROS), which may in part explain the vasoconstriction following weaning of $\mathrm{CPB}$ due to scavenging of $\mathrm{NO}$ by $\mathrm{ROS}^{7}{ }^{7} \mathrm{PGI}_{2}$ has cytoprotective effects due to its ability to scavenge the ROS and reduces the synthesis of proinflammatory cytokines such as tumor necrosis factor $\alpha .{ }^{7}$ In the current study, the antioxidant activity was measured from the right atrium instead of lung tissue or left atrium plasma, which may explain in part the lack of difference between the CPB and the $\mathrm{PGI}_{2}$ groups.

\section{Clinical Implications}

Congenital heart disease and pretransplantation status are frequently associated with a preexisting pulmonary hypertension. Inhaled $\mathrm{PGI}_{2}$ has been used to evaluate the reversibility of pulmonary hypertension of potential candidates for heart transplantation. ${ }^{25}$ To our knowledge, no study has examined the role of pre-CPB use of vasodilators such as $\mathrm{PGI}_{2}$ and $\mathrm{NO}$ to prevent post-CPB pulmonary hypertension. The inhaled form is especially effective due to pulmonary selectivity and prevention of hypotension, which could be deleterious in high-risk patients.

\section{Limitations}

The amount of inhaled $\mathrm{PGI}_{2}$ reaching the alveoli cannot be precisely determined due to drug deposition in the ventilator and orotracheal tubing. Data have demonstrated that there is less than $10 \%$ of alveolar deposition of drug during mechanical ventilation. ${ }^{26}$ However, the $\mathrm{PGI}_{2}$ concentration use in our study was comparable to other published studies ${ }^{12,26}$ with evident hemodynamic results. There was no inhalation of a placebo in the CPB group, so we cannot exclude a possible interference of CPAP on our results and the inhaled route of delivery may be responsible for the improvement in the A-a gradient. However, it has been previously demonstrated that a CPAP of $5 \mathrm{~cm} \mathrm{H}_{2} \mathrm{O}$ does not prevent the post-CPB lung function impairment. ${ }^{27}$ Also, the $\mathrm{PGI}_{2}$ group has not been compared with an inhaled glycine group, the 
buffer vehicle used to transport $\mathrm{PGI}_{2}$ molecules. However, glycine has no hemodynamic and respiratory parameter influence and is not associated with major signs of acute pulmonary toxicity. ${ }^{28,29}$ Use of healthy swine in this study instead of a model with pre-CPB pulmonary hypertension could have minimized our results. Finally, a species specificity of swine intravascular macrophages cannot be excluded, which could limit the clinical relevance of the present study.

\section{Conclusion}

CPB causes an increase in pulmonary vascular resistance, which may induce RV dysfunction. Also, the inflammatory response associated with CPB impairs endothelium-dependent relaxation, which can further contribute to pulmonary hypertension. Administration of inhaled $\mathrm{PGI}_{2}$ during $\mathrm{CPB}$ improves the endothelial dysfunction via an increase of the cAMP content of pulmonary arteries and partially compensates for the decrease in endothelial production of NO. Inhaled $\mathrm{PGI}_{2}$ also stabilizes the mPAP and maintains the oxygen exchanges $\left(\mathrm{A}-\mathrm{aDO}_{2}\right)$. Clinical studies should be undertaken to determine the impact of inhaled $\mathrm{PGI}_{2}$ on post-CPB hemodynamic and lung function.

We thank Sylvie Lévesque of the Department of Biostatistics of the Montreal Heart Institute for the statistical work and France Thériault for the preparation of the manuscript.

\section{References}

1. Kolff WJ, Effler DB, Groves LK, Hughes CR, McCormack LJ. Pulmonary complications of open-heart operations: their pathogenesis and avoidance. Cleve Clin Q. 1958;25:65-83.

2. Ng CS, Wan S, Yim AP, Arifi AA. Pulmonary dysfunction after cardiac surgery. Chest. 2002;121:1269-77.

3. Wan S, LeClerc JL, Vincent JL. Inflammatory response to cardiopulmonary bypass: mechanisms involved and possible therapeutic strategies. Chest. 1997;112:676-92.

4. Boyle EM Jr, Pohlman TH, Johnson MC, Verrier ED. Endothelial cell injury in cardiovascular surgery: the systemic inflammatory response. Ann Thorac Surg. 1997;63:277-84.

5. Higenbottam TW, Laude EA. Endothelial dysfunction providing the basis for the treatment of pulmonary hypertension: Giles F. Filley lecture. Chest. 1998;114:72S-9S.

6. Chen YF, Oparil S. Endothelial dysfunction in the pulmonary vascular bed. Am J Med Sci. 2000;320:223-32.

7. Scheeren T, Radermacher P. Prostacyclin (PGI2): new aspects of an old substance in the treatment of critically ill patients. Intensive Care Med. 1997;23:146-58.

8. Haché M, Denault AY, Belisle S, Couture P, Babin D, Tetrault F, et al. Inhaled prostacyclin (PGI2) is an effective addition to the treatment of pulmonary hypertension and hypoxia in the operating room and intensive care unit. Can J Anaesth. 2001;48:924-9.

9. Max M, Rossaint R. Inhaled prostacyclin in the treatment of pulmonary hypertension. Eur J Pediatr. 1999;158(Suppl 1):S23-6.

10. Gagnon J, Desjardins N, Malo O, Carrier M, Perrault LP. Mechanism of pulmonary artery endothelial dysfunction secondary to cardiopulmonary bypass. Canadian Perfusion. 2001;11:8-16.

11. Carr JA, Silverman N. The heparin-protamine interaction. A review. J Cardiovasc Surg (Torino). 1999;40:659-66.

12. Haché M, Denault AY, Belisle S, Robitaille D, Couture P, Sheridan P, et al. Inhaled prostacyclin and pulmonary hypertension in cardiac surgery. J Thorac Cardiovasc Surg. 2003;125:642-9.

13. Riedel B. The pathophysiology and management of perioperative pulmonary hypertension with specific emphasis on the period following cardiac surgery. Int Anesthesiol Clin. 1999;37:55-79.

14. Morita K, Ihnken K, Buckberg GD, Sherman MP, Ignarro LJ. Pulmonary vasoconstriction due to impaired nitric oxide production after cardiopulmonary bypass. Ann Thorac Surg. 1996;61:1775-80.

15. Davila-Roman VG, Waggoner AD, Hopkins WE, Barzilai B. Right ventricular dysfunction in low output syndrome after cardiac operations: assessment by transesophageal echocardiography. Ann Thorac Surg. 1995;60:1081-6.

16. Maslow AD, Regan MM, Panzica P, Heindel S, Mashikian J, Comunale ME. Precardiopulmonary bypass right ventricular function is associated with poor outcome after coronary artery bypass grafting in patients with severe left ventricular systolic dysfunction. Anesth Analg. 2002;95:1507-18.

17. Downing SW, Edmunds LH Jr. Release of vasoactive substances during cardiopulmonary bypass. Ann Thorac Surg. 1992;54:1236-43.

18. Schwinn DA, McIntyre RW, Hawkins ED, Kates RA, Reves JG. Alpha 1-adrenergic responsiveness during coronary artery bypass surgery: effect of preoperative ejection fraction. Anesthesiology. 1988;69: 206-17.

19. Wachtogel YT, Musial J, Jenkin B, Niewiarowski S, Edmunds LH Jr, Colman RW. Loss of platelet alpha 2-adrenergic receptors during simulated extracorporeal circulation: prevention with prostaglandin E1. J Lab Clin Med. 1985;105:601-7.

20. McMullan DM, Bekker JM, Parry AJ, Johengen MJ, Kon A, Heidersbach RS, et al. Alterations in endogenous nitric oxide production after cardiopulmonary bypass in lambs with normal and increased pulmonary blood flow. Circulation. 2000;102(Suppl 3):III172-8.

21. Liu SF, Barnes PJ. Role of endothelium in the control of pulmonary vascular tone. Endothelium. 1994;2:11-33.

22. Zanaboni P, Murray PA, Simon BA, Zehr K, Fleischer K, Tseng E, et al. Selective endothelial dysfunction in conscious dogs after cardiopulmonary bypass. J Appl Physiol. 1997;82:1776-84.

23. Kamper AM, Paul LC, Blauw GJ. Prostaglandins are involved in acetylcholine- and 5-hydroxytryptamine-induced, nitric oxide-mediated vasodilatation in human forearm. J Cardiovasc Pharmacol. 2002; 40:922-9.

24. Zhang X, Hintze TH. cAMP signal transduction cascade, a novel pathway for the regulation of endothelial nitric oxide production in coronary blood vessels. Arterioscler Thromb Vasc Biol. 2001;21:797803.

25. Weston MW, Isaac BF, Crain C. The use of inhaled prostacyclin in nitroprusside-resistant pulmonary artery hypertension. J Heart Lung Transplant. 2001;20:1340-4.

26. Haraldsson A, Kieler-Jensen N, Wadenvik H, Ricksten SE. Inhaled prostacyclin and platelet function after cardiac surgery and cardiopulmonary bypass. Intensive Care Med. 2000;26:188-94.

27. Magnusson L, Zemgulis V, Wicky S, Tyden H, Hedenstierna G. Effect of CPAP during cardiopulmonary bypass on postoperative lung function. An experimental study. Acta Anaesthesiol Scand. 1998;42:1133-8.

28. Kleen M, Habler O, Hofstetter C, Pusch R, Mueller M, Welte M, Zwissler B. Efficacy of inhaled prostanoids in experimental pulmonary hypertension. Crit Care Med. 1998;26:1103-9.

29. Habler O, Kleen M, Zwissler B, et al. Inhalation of prostacyclin $\left(\mathrm{PGI}_{2}\right)$ for 8 hours does not produce signs of acute pulmonary toxicity in healthy lambs. Intensive Care Med. 1996;22:426-433. 